\title{
Protective effects of amniotic fluid in the setting of necrotizing enterocolitis
}

\author{
Soham Dasgupta ${ }^{1}$ and Sunil Kumar Jain ${ }^{1}$
}

Necrotizing enterocolitis (NEC) is the most common life threatening condition affecting preterm infants. NEC occurs in $1-5 \%$ of all neonatal intensive care admissions and $5-10 \%$ of very low birth weight infants. The protective role of human breast milk (BM) has been well established. It has also been shown that amniotic fluid (AF) and BM have many similarities in terms of presence of growth and other immunemodulatory factors. This finding led to the initial hypothesis that AF may exert similar protective effects against the development of NEC, as does BM. Multiple studies have elucidated the presence of growth factors in AF and the protective effect of AF against NEC. Studies have also described possible mechanisms how AF protects against NEC. At present, research in this particular area is extremely active and robust. This review summarizes the various studies looking at the protective effects of AF against the development of NEC. It also provides an insight into future directions, the vast potential of AF as a readily available biologic medium, and the ethical barriers that must be overcome before using AF.

$\mathbf{N}$ ecrotizing enterocolitis (NEC) is a gastrointestinal inflammatory disease, which affects predominantly preterm infants. Bell-staging criteria (1) is most commonly used to define the severity of NEC. NEC is the most common life threatening condition affecting preterm infants (PI) (2). NEC occurs in $1-5 \%$ of all neonatal intensive care admissions and $5-10 \%$ of all very low birth weight $(<1,500 \mathrm{~g})$ infants (3) leading to high morbidity and mortality. Patel et al. (4) showed that NEC has emerged as the leading cause of mortality in extremely low birth weight infants. The study found that in extremely PI, overall mortality related to pulmonary, immaturity, infection, and central nervous system (2000-2011) has declined. However, mortality secondary to NEC has increased during the same time period. Intestinal perforation, short gut syndrome, and TPN-associated cholestasis are the common causes of morbidity and mortality related to NEC $(5,6)$. Long-term adverse outcomes include stricture formation, development of recurrent NEC, and development of short bowel syndrome (7). In 2011, overall cost of taking care of medical NEC was $\$ 74,004$ and surgical NEC was $\$ 198,040$ per infant, respectively (8).

After more than half a century of NEC research in animal models and in vitro research, we could not find a "magic bullet" to prevent NEC. However, in last decade the most effective tools to decrease burden of NEC have been NEC prevention initiatives like breast milk (BM) feeding, blood transfusion guidelines, and antibiotics stewardship in PI $(3,9,10)$. During fetal life, fetal intestine gets exposed to high concentrations of many trophic factors by swallowing AF. But preterm birth interrupts AF swallowing, which deprives the intestine of PI of these trophic factors. In this review, we will review the role of various trophic factors and cytokines in the development of intestine and role of decreasing/preventing NEC by providing trophic factors via supplementing AF.

\section{PATHOGENESIS}

The pathogenesis of NEC is complex and multifactorial. Prematurity, bacterial colonization of the gut, and formula feeding are the three main factors responsible in the pathogenesis of NEC. Prematurity leads to impaired peristalsis, deficiencies in components of the mucus layer, and disruption of the integrity of the intestinal tract epithelial tight junctions (11).

\section{Role of Toll-Like Receptor 4 in Pathogenesis of NEC}

Toll-like receptor 4 (TLR4) is an innate immune receptor that recognizes lipopolysaccharide (LPS) found in Gram-negative bacteria. TLR4 is expressed at higher levels in the premature than the full-term intestine in human infants, rodents, and other species (12). TLR4 is expressed at high levels in developing fetal intestine. After preterm birth, intestinal TLR4 levels remain high, gut bacterial colonization during postnatal period leads to exaggerated activation of TLR4 signaling. This exaggerated activation of TLR4 leads to development of NEC in premature infants by increased enterocyte apoptosis, impaired mucosal healing, and enhanced pro-inflammatory cytokine release (13). The intestine of PI have increased bacterial colonization, altered microcirculatory perfusion, and the immaturity of the immune system compared with term infants $(12,13)$. These factors work together to develop NEC in PI. 


\section{Gut Bacterial Colonization of Premature Infants}

Gut colonization of pathological Gram-negative bacteria in PI leads to an alteration of the normal gut flora. Colonization of the gut in the early neonatal period happens in two waves (14). The first wave, which is similar in both term and PI, predominantly depends on the mode of childbirth. The second wave of colonization in term infants is determined by feeding type. Breastfed infants mainly have Bifidobacterial Bacteroides and formula-fed infants predominantly have Streptococci/Staphylococci/Lactobacilli (15). In the case of PI, the second wave of colonization is influenced less by the type of feeding, and is characterized by high numbers of Clostridiaceae and Enterobacteriaceae and very low relative numbers of Bifidobacteria and Bacteroides. Several investigators have shown a link between this abnormal gut microbiota in PI and the development of NEC. PI are also exposed to longer courses and duration of antibiotic therapy, which may lead to significant alteration of the flora of the normal gastrointestinal tract (GIT) (3).

Even though TLR4 has significant role in the pathogenesis of NEC, other pathways have been shown to be important as well. Increased expression of platelet-activating factor in gut mucosal injury and intestinal epithelial barrier function is associated with NEC (16).

Pro-inflammatory cytokines like LPS cause epithelial injury leading to epithelial barrier injury and development of NEC via nitric oxide. Ford et al. compared iNOS mRNA in the intestinal tissue from infants with and without NEC. iNOS mRNA levels were significantly higher in the intestinal samples from infants who had NEC compared with controls. Further, immunochemistry and in situ hybridization confirmed that the predominant source of iNOS activity was enterocytes in the intestinal samples from infants with $\operatorname{NEC}(17,18)$.

Understanding the exact pathogenesis of NEC is crucial to implementing strategies to prevent it. Human BM and amniotic fluid (AF) have been shown to contain numerous bio-factors that may be protective against the development of NEC in PI. This is discussed further in this review article.

\section{FETAL SWALLOWING OF AF}

The fact that NEC is not seen in utero raised the possibility of the presence of protective factors in AF against the development of NEC. AF is the first environmental exposure contributing to GIT development, and the AF cavity is identified early in embryogenesis (19). Initially, it is predominantly composed of water and solute from maternal plasma that is delivered to the fetus actively via the placenta and diffuses from the non-keratinized fetal tissues into the amniotic space. During second half of pregnancy, fetus actively contributes to the volume and composition of the AF, mainly through swallowing and urination (20). Starting at 8-11 weeks' gestation, the fetus ingests increasing amounts of AF that may reach $500 \mathrm{ml} /$ day in the third trimester (20). In a fetal sheep model $(21,22)$, interruption of AF ingestion by esophageal ligation caused mucosal atrophy, villus blunting, and enterocyte abnormalities. Neonates born with congenital intestinal obstruction also showed villus blunting and poorly organized crypts distal to the site of obstruction (23). In the sheep model, the effects of interrupted AF swallowing on the intestinal mucosa were gradually reversed following the removal of esophageal ligatures and restitution of AF ingestion, but not with infusion of lactated Ringer's solution. These findings indicated that the trophic effects of AF were secondary to the bioactive molecules present in AF rather than due to the flow of fluid through the gut (23). There are many trophic factors in AF like insulin-like growth factors I and II (IGF I and II), epidermal growth factor (EGF), hepatocyte growth factor (HGF), and others that modify intestinal nutrient absorption and development, which are reviewed in Drozdowski and Thomson (24).

\section{EFFECT OF CYTOKINES ON THE DEVELOPMENT OF THE GIT}

The development, maturation, and maintenance of the complex functions of the GIT require interaction with multiple environmental exposures. Maheshwari (25) described cytokines in AF and their role in the development of GIT. In addition to the cytokines and growth factors delivered to the intestinal mucosa via AF, the fetal GIT also constitutively expresses many cytokines and growth factors at high levels. Intestinal epithelial cells express receptors for most of these cytokines, and evidence from in vitro and animal models suggest that many of these agents can increase enterocyte proliferation, migration, and differentiation, prevent apoptosis, and promote mucosal restitution, all of which protect against NEC $(19,26)$.

The cytokines described by Maheshwari et al. and their role in the development of the GIT are described in Table 1.

\section{ROLE OF ANTIMICROBIAL PEPTIDES IN AMNIOTIC FLUID}

Antimicrobial proteins and peptides (APP) serve as a broad spectrum anti-infective molecules. AF is a good source of many APP like neutrophil defensins, bactericidal permeability increasing proteins, calprotectin, and human B defensin-2 (HBD-2) among others $(27,28)$. These APP account for the antimicrobial activity of the AF, and their concentrations increase under conditions where there is microbial invasion of the amniotic cavity. APPs are believed to be significantly alter environmental microbiota and influence expression of pattern-recognition receptors at the intestinal epithelial surface. Low levels of defensins in PI are associated with the increased incidence of NEC (13). Ileal tissues from the infants with NEC show elevated defensin levels compared with controls, indicating that at some stage in the pathogenesis of NEC, paneth cells are stimulated to produce increased defensins (29). Higher HBD-2 concentrations appear to have a protective effect once NEC is established and lead to a more moderate courses of the disease. In severe NEC, low HBD-2 expression may suggests an inadequate response to luminal bacteria, which may predispose to the development of NEC (30). APP appear to have an important protective role in the 


\section{Review | Dasgupta and Jain}

Table 1. Roles of various trophic factors found in $\mathrm{AF}$ in the development of the gastrointestinal tract

\begin{tabular}{|c|c|c|}
\hline Cytokine & Location & Effects on GIT development \\
\hline \multicolumn{3}{|c|}{ Cytokine receptor superfamily class 1} \\
\hline Erythropoietin & Present in $\mathrm{BM}$ and $\mathrm{AF}$ & Crypt cell proliferation, villus growth, and intestinal growth (104) \\
\hline Interleukin 2 & Present in $\mathrm{BM}$ and $\mathrm{AF}$ & It is present in BM and AF, and may aid in mucosal repair (49) \\
\hline Interleukin 4 & Present in $\mathrm{BM}$ and $\mathrm{AF}$ & $\begin{array}{l}\text { Potent inducer of decay-accelerating factor (DAF), suggesting a } \\
\text { protective role against autologous-complement activation (50) }\end{array}$ \\
\hline Interleukin 6 & Present in $\mathrm{BM}$ and $\mathrm{AF}$ & $\begin{array}{l}\text { It has been shown to stimulate villus growth and mucosal enzyme } \\
\text { development (51) }\end{array}$ \\
\hline Interleukin 7 & Present in $\mathrm{BM}$ and $\mathrm{AF}$ & Primarily involved in formation of gut lymphoid tissue (52) \\
\hline Interleukin 11 & Present in $\mathrm{BM}$ and $\mathrm{AF}$ & $\begin{array}{l}\text { Preserves the epithelial barrier and villus height by decreasing } \\
\text { apoptosis (53) }\end{array}$ \\
\hline
\end{tabular}

Cytokine receptor superfamily class 2

Interleukin 10

Present in $\mathrm{BM}$ and $\mathrm{AF}$

Mucosal maintenance after birth (106)

Cytokine receptor superfamily class 3

TNF-X

Present in $\mathrm{BM}$ and $\mathrm{AF}$

Effects on apoptosis (107)

Cytokine receptor superfamily class 4

Interleukin 1

Present in $\mathrm{BM}$ and $\mathrm{AF}$

Intestinal epithelial cell proliferation, increased nutrient uptake, and cyclooxygenase activation (54)

Receptor tyrosine class 1 family

EGF

Present in $\mathrm{BM}$ and $\mathrm{AF}$

Potent stimulus to epithelial cell proliferation(108)

TGF-X

Present in $\mathrm{BM}$ and $\mathrm{AF}$

Crypt cell proliferation and mucosal repair (109)

Receptor tyrosine class 2

IGF-1 and 2

Present in $\mathrm{BM}$ and $\mathrm{AF}$

Crypt cell proliferation and mucosal repair (45)

HGF

Present in $\mathrm{BM}$ and $\mathrm{AF}$

Crypt cell proliferation (39)

Receptor tyrosine class 3

VEGF

Present in $\mathrm{BM}$ and $\mathrm{AF}$

Crypt cell proliferation (110)

Receptor tyrosine class 4

FGF

Present in $\mathrm{BM}$ and $\mathrm{AF}$

Intestinal epithelial cell proliferation (46)

Receptor serine kinases

TGF-B

Present in $\mathrm{BM}$ and $\mathrm{AF}$

Intestinal epithelial cell proliferation and differentiation (39)

$G$ protein-coupled receptors

Interleukin 8

Present in $\mathrm{BM}$ and $\mathrm{AF}$

Migration and proliferation and induces many differentiation related activities in intestinal epithelial cells (111)

EGF, epidermal growth factor; FGF, fibroblast growth factor; G-CSF, granulocyte colony-stimulating factor; HGF, hepatocyte growth factor; IGF-1, insulin-like growth factor-1; TGF- $\alpha$ and TGF- $\beta$, transforming growth factor $a$ and $\beta$; TNF-X, tumor necrosis factor; VEGF, vascular endothelial growth factor. 
pathogenesis of NEC, and their presence in AF raises the potential use of AF to protect PI from NEC.

\section{ROLE OF TROPHIC FACTORS FOUND IN AF IN THE PREVENTION OF DEVELOPMENT OF NEC}

The AF contains many trophic factors (TF), which are responsible for the growth and development of the GIT. However, a lot of these TF are also involved in the protection of the fetal GIT against mucosal injury. Some relevant TF includes:

(1) Epidermal growth factor (EGF): In 1962, a growth factor was discovered from mouse saliva, which could induce premature eruption of the teeth and opening of eyelids-that is why it was called epidermal growth factor (EGF) (31). EGF is a family of peptides that share structure and affinity to the EGF receptor. It is a small peptide that functions as a luminal surveillance peptide that can attach to the EGF receptor on the basolateral membrane when the luminal barrier is damaged (32). As the GIT is an important barrier to outside noxious substances, there is quick healing of injured epithelial lining by epithelial migration and proliferation, called restitution (33). EGF stimulates restitution of the superficial epithelial lining of GIT. It stimulates cell mitosis and differentiation, decreases acid secretion, increases bicarbonate, mucus secretions, and GIT blood flow, and helps in digestion by increasing amylase secretions and by increasing gastric motility. EGF is also a cytoprotective molecule that can stabilize GIT epithelial cells from agents like ethanol or non-steroidal anti-inflammatory drugs (34). EGF has two main physiological functions: (i) involved in mucosal protection and healing of damaged epithelial lining and (ii) involved in digestion, absorption, and transportation of nutrients. EGF supplementation has been shown to protect rat pups against NEC-like injury. In preclinical models, EGF promotes the maturation of the intestinal barrier, reduces enterocyte apoptosis, and downregulates the inflammatory response associated with NEC-like injury (35-37).

(2) Hepatocyte growth factor (HGF): It is present in AF and human milk, and is expressed in embryonic and fetal intestinal tissue (38). The HGF receptor, C-meta proto-oncogene, is present on intestinal crypt epithelial cells although it is also expressed in the muscle layers of the intestine $(26,39)$. HGF stimulates intestinal cell proliferation in vitro and has been demonstrated to induce intestinal growth in rats when administered in pharmacologic doses (38). In an animal model of NEC, we showed that oral supplementation of $\mathrm{AF}$ is protective against experimental NEC in a rat model of NEC (hypoxia and hypothermia model), which was mediated, at least partly, by HGF.

(3) Transforming growth factor- $\alpha$ (TGF- $\alpha$ ): It is detectable in the human GIT at 15 weeks gestation (38). It has a structure similar to EGF and binds to the same receptor. Recombinant TGF- $\alpha$ has been shown to elicit a synergistic trophic response on cultured intestinal cells when combined with EGF, IGF-1, FGF, and HGF (40). Its primary role is believed to be in mucosal repair (38).

(4) Transforming growth factor- $\beta$ (TGF- $\beta$ ): It belongs to a family of signaling peptides that influences the distribution of intestinal stem cells. It is believed to induce terminal differentiation of intestinal epithelial cells and to accelerate the rate of healing of intestinal wounds by stimulating cell migration (19). A role in the prevention of necrotizing enterocolitis has been suggested as well (41). We showed that TGF $\beta$, especially TGF $\beta 2$, suppresses macrophage inflammatory responses in the developing intestine and protects against mucosal inflammatory injury. We further showed that enteral feeding of TGF 32 -protected mice from experimental NEC-like injury (42). Orallyingested TGF- $\beta$ promotes gut barrier function, immune tolerance, and mucosal repair in the neonatal gastrointestinal tract $(43,44)$.

(5) Insulin-like growth factors (IGF-1 and IGF-2): It has been shown to increase somatic growth and bowel wall thickness in human duodenal explants (45).

(6) Fibroblast growth factor (FGF): Studies have demonstrated that inhibition of FGF activity in AF causes a $58 \%$ reduction in AF-induced intestinal epithelial cell proliferation $(40,46)$.

(7) Erythropoietin (EPO): It has been shown that administration of recombinant EPO increases villus height, villus area, crypt depth, and crypt epithelial cell proliferation in rat pups $(26,33)$. In vitro, recombinant EPO has been shown to protect cells against mucosal injury, and the incidence of NEC is reported to be lower in neonates who received recombinant EPO (47).

(8) Granulocyte colony-stimulating factor (G-CSF): There is evidence that G-CSF may have a role in epithelial cell maintenance (48). Sections of fetal intestines at $8-10,16-18$, and 22-24 weeks" postconceptual age have demonstrated the presence of G-CSF-receptors (G-CSFR). At 8-10 weeks' postconceptual age, G-CSF-R was present in nuclei within the mucosal epithelium and was occasionally prominent at the base of the crypts. At 16-18 weeks, it was only evident within the smooth muscle and by 24 weeks, it was detected at the apex of the mucosal epithelium in developing enterocytes and within the basally located nucleus.

(9) Interleukin family (IL): IL-2 is believed to enhance intestinal epithelial cell restitution, and there is evidence that IL-2 has a crucial role in mucosal healing because IL-2 knockout mice develop colitis similar to human ulcerative colitis (49). IL-4 is believed to enhance the integrity of the intestinal epithelial cell junctions (50). IL-6 may have a role in protecting intestinal cells against apoptosis secondary to hypoxia or other severe 
insults (51). IL-7 is primarily involved in the formation of the gut lymphoid tissue, and IL-7 receptor knockout mice have higher radio-sensitivity and crypt cell apoptosis (52). IL-11 has been shown to preserve the epithelial barrier and villus height by decreasing apoptosis. It has demonstrated a trophic effect during adaptation after intestinal resection (53). IL-1 has been shown to induce intestinal epithelial cell proliferation and increased nutrient uptake. In rat intestine, IL-1 expression increased at the time of weaning and correlated with the onset of crypt cell proliferation (52). IL-1 has also been shown to induce expression of decay-accelerating factor, which is responsible for the degradation of activated complement (protective role against complement activation) (54).

\section{ROLE OF BM IN THE PREVENTION OF DEVELOPMENT OF NEC}

Growth factors such as EGF, TGF- $\alpha$ and IGF-1, and many more (which are the same TF found in AF) elicit trophic effects on the neonatal GIT, and promote proliferation and differentiation of epithelial cells (55). These factors promote a rapid enterocyte turnover from the crypt to the villus tip. Several peptides of human milk with antimicrobial activity (lactoferrin) are capable of influencing intestinal development $(56,57)$. Lactoferrin is found in colostrum and in mature BM, and promotes intestinal differentiation (58). In a large prospective trial, BM was protective against NEC (6-10 times less than those fed formula exclusively) (59). Bile acid-related ileal damage was seen to be higher in formula-fed infants than breastfed infants (60). EGF, which is present in BM, also limits ileal damage from bile acids and has been shown to be protective against NEC (61). Human milk oligosaccharides (HMO) are present in large amounts in BM and are hardly digested/absorbed by the infant, but they traverse the alimentary canal and exhibit three major activities (62). First, the glycans of milk, have carbohydrate moieties that are analogous to those found on the glycans of the intestinal mucosal surface. Thus, they compete for binding to the adhesins of bacteria and capsid proteins of viruses, thereby protecting the gut from infection by these pathogens. Second, the oligosaccharides are prebiotic and are indigestible by the host. Prebiotics inhibit infection through acidifying the gut lumen. Third, new evidence demonstrates that HMO directly inhibit inflammation through modulation of signaling pathways. Good et al. (63) suggested that the presence of HMO in BM protects against NEC by enhancing mucosal blood flow. They demonstrated that this protection was afforded by maintenance of mesenteric perfusion via the upregulation of endothelial nitric oxide synthase. Meinzen-Derr et al. (64) also showed a dose-related association of BM feeding with a reduction of NEC or death in the first 2 weeks of life among extremely low birth weight infants. Good et al. (65) demonstrated various factors in BM, which have a protective role against NEC.
Table 2. The various trophic factors that are found in both amniotic fluid and human BM

\begin{tabular}{l}
\hline Trophic factors found in AF and human BM \\
\hline Epidermal growth factor (EGF) \\
Transforming growth factor-B (TGF-B) \\
Insulin-like growth factor-1 (IGF-1) \\
Interleukins \\
Lactoferrin \\
Immunoglobulins \\
\hline
\end{tabular}

It has been demonstrated that many of the bioactive factors contained in human BM are also present in AF (Table 2) (66). There are similarities between the prenatal biology of AF and the postnatal biology of BM in terms of presence of growth and other immune-modulatory factors. These factors are not only important for the development of the fetal GIT as described earlier, but also may have a vital role in the prevention of NEC in preterm infants. This led to the hypothesis that whether $\mathrm{BM}$ is protective against the development of NEC, could AF be administered postnatally? Would it have the same degree of protection against NEC because of the many similar properties in these two biological media? This drove subsequent studies (discussed later in review) aimed at demonstrating similarities in mechanisms of protection afforded by both $\mathrm{AF}$ and $\mathrm{BM}$ against NEC.

ROLE OF TLR4 RECEPTOR IN THE PATHOGENESIS OF NEC Several studies have shown that enterocytes can constitutively express pro-inflammatory cytokines (IL-8, TNF, $\gamma$-INF, and IL-1) (67), and this response is upregulated by inflammatory stimuli such as LPS and IL-1 $\beta$ (68). This upregulation of proinflammatory cytokines may be mediated by the transcription factor NF-KB (69). Nanthakumar et al. (70) demonstrated an enhanced IL- 8 response by fetal enterocytes when stimulated with LPS, and IL-1 $\beta$ compared with enterocytes from older children. They also noted that the response to stimulation with IL- $1 \beta$ in fetal enterocytes was much greater than that of the LPS response. This led them to speculate that receptor expression or the signal transduction activation response to IL- $1 \beta$ may be more highly developed in fetal intestine than is that for the LPS response. The LPS stimulus via a TLR signal transduction pathway (described below) is likely divergent from that of the IL-1 $\beta$ pathway and may not be as upregulated. Alternatively, the capacity of LPS to bind with its receptor may not be completely developed in the immature intestinal milieu, and therefore may produce a lesser IL-8 enterocyte upregulation when interacting with TLRs than the IL-1 $\beta$ receptors.

Recent studies have identified a critical role for the LPS receptor, TLR4, in the pathogenesis of NEC. Studies have demonstrated that circulating levels of LPS are elevated in patients with NEC, and that animal models of NEC are also associated with the increased levels of LPS in the plasma and 
stool $(71,72)$. A specific role for Gram-negative bacterial LPS in the pathogenesis of NEC was supported by the results of studies performed in newborn rats and piglets in which the oral or intravenous administration of LPS was associated with intestinal mucosal NEC-like injury (73). The membranebound receptor, TLR4 mediates the signaling of LPS within mammalian cells $(74,75)$. It has been demonstrated in myeloid cells that LPS activation of TLR4 stimulates a downstream pro-inflammatory cascade with release of cytokines such as IL-1 and NF- $\kappa \beta$ (76). Several studies have also indicated that enterocytes respond to LPS via TLR4 and its associated molecules. This raised the possibility that activation of TLR4 in vivo by LPS may participate in the signaling events that lead to NEC. Leaphart et al. demonstrated that animals expressing wild-type TLR4 developed significantly increased severity of NEC compared with TLR4mutant counterparts, due to an increase in enterocyte loss by apoptosis and a reduced capacity of the TLR4-wild-type mice to undergo intestinal repair. They hypothesized that in response to significant LPS/hypoxic stress, TLR4 expression and signaling are increased in the newborn intestines, rendering it increasingly susceptible to endotoxin upon its subsequent colonization by Gram-negative flora. The resultant activation of TLR4 within the enterocyte tips the balance toward apoptotic injury, which then impairs the repair mechanisms through negative effects on proliferation and migration. These findings describe the importance of TLR4 in regulating the balance between injury and repair in the intestine (77).

This extremely important finding enabled future studies to elucidate the mechanisms of protection afforded by $\mathrm{AF}$ and $\mathrm{BM}$ against the development of NEC.

\section{MECHANISM OF PROTECTION OF AF AND BM AGAINST THE DEVELOPMENT OF NEC}

After many studies had demonstrated the protective effects of $\mathrm{AF}$ and $\mathrm{BM}$ against NEC, it was important to elucidate the mechanisms involved. Jantscher-Krenn et al. (78) showed human milk oligosaccharides, specially disialyllacto-N-tetraose, complex glycans are present in human milk, which are responsible for the beneficial effects in NEC in neonatal rats. If this research can be translated to NEC in human neonates, it may prevent or reduce the burden of NEC in neonates. Good et al. demonstrated the effects of LPS-mediated TLR4 activation on mucosal injury and repair, and the subsequent development of NEC. They hypothesized that AF can inhibit TLR4 signaling within the fetal intestine and attenuate experimental NEC (79). This would become the study based on which the mechanisms of the protective effect of $\mathrm{BM}$ against the development of NEC were also demonstrated (80). We have focused on two important studies to highlight the protective effects of $\mathrm{AF}$ and $\mathrm{BM}$ against the development of NEC.

\section{Study 1: Mechanism of AF Against the Development of NEC} (Mice Study)

Intestinal epithelium in utero. Good et al. (79) demonstrated that the delivery of LPS into the fetal gut resulted in a significant increase in the expression of TLR4 signaling and pro-inflammatory cytokines. However, the coadministration of AF and LPS into the GIT markedly reduced the extent of TLR4 signaling within the intestinal mucosa. These findings demonstrated that AF could inhibit TLR4 signaling in the fetal intestinal epithelium.

Cultured enterocytes. The second part of the study hypothesized that EGF (a major TF found in AF) was responsible for the inhibition of TLR4 expression. They demonstrated that EGF caused a significant reduction in LPS-mediated TLR4 activation, effects which were absent when the EGF receptor (EGFR) was knocked out.

Fetal intestinal epithelium. They subsequently demonstrated that AF inhibited TLR4 signaling via the EGFR within the developing intestine as well. This was done by the administration of AF+LPS directly into fetal mice GIT. The addition of an EGFR inhibitor attenuated the protective effect of AF on TLR4 signaling.

Postnatal intestine. They finally demonstrated that AF attenuated TLR4 signaling in the postnatal intestine as well. Enteral administration of AF significantly attenuated NEC severity (reduction in the expression of iNOS within the intestinal mucosa, restoration in enterocyte proliferation, preservation of mucosal architecture, and a marked reduction in the histology scores) in mice, where NEC was induced by hypoxia and formula feeds. Again, pre-treatment of mice with an EGFR inhibitor or the enteral administration of AF that was immune-depleted of EGF markedly reduced the protective effects of AF on NEC severity.

The study identified EGFR activation as the possible pathway leading to TLR4 inhibition within the fetal and neonatal GIT. They also demonstrated that EGF, which is present in vast abundance in AF, mediated this pathway. Their findings emphasized the role of AF in the protection against NEC.

\section{Study 2: Mechanism of BM Against the Development of NEC (Mice Study)}

Cultured enterocytes. The first part of the study demonstrated that pre-treatment of enterocytes with BM significantly reduced the extent of LPS-induced TLR4mediated activation of pro-inflammatory cytokines (similar to administration of AF) (80).

In vivo. This protective effect was not seen in EGFR knockout mice suggesting that the activation of EGFR may be responsible for such a protective effect. They also showed that BM inhibits TLR4 activation in vivo via EGFR activation 
Developing intestine. They demonstrated that pretreatment of mice with BM significantly reduced enterocyte apoptosis and proliferation, which is seen in experimental models of NEC. In the developing intestine, the administration of BM+LPS+EGFR inhibitor or the addition of EGF-depleted $\mathrm{BM}$ reversed these protective effects (similar to $\mathrm{AF}$ ).

In summary, the two studies demonstrated that both BM and AF attenuated experimental NEC via inhibition of TLR4 signaling through EGFR activation. The fact that EGF is present in abundance in $\mathrm{BM}$ and in $\mathrm{AF}$ raised the vast possibility of using $\mathrm{AF}$ as a medium and fluid to prevent the development of NEC in PI.

\section{PROTECTIVE EFFECT OF AF IN THE SETTING OF NEC-WHAT IS KNOWN}

Siggers et al. (66) used porcine AF from 30 preterm pigs in late gestation. Preterm pigs were delivered by cesarean section and fed parenteral nutrition (2 days) followed by enteral nutrition (2 days) (porcine colostrum or infant formula or AF). For the first part of their experiment, AF was supplemented during parenteral and subsequent enteral nutrition, and in the second part AF was only supplemented during enteral nutrition. A variety of methods were then used to evaluate the GIT for signs of NEC. Pigs fed AF during parenteral and enteral nutrition had lower macroscopic NEC scores as compared with formula-fed pigs; however, there was no difference in NEC scores when pigs were fed AF only during enteral nutrition. Increased galactose absorption was noted in AF-fed pigs as compared with formula-fed pigs. Inflammatory mediators such as IL- 1 and TNF- $\alpha$ were found to be downregulated in pigs fed with AF during both the parenteral and enteral nutrition phase, which was measured by microarray analysis of frozen GIT samples. TNF- $\alpha$ production showed a dose-dependent decrease as AF concentrations increased, highlighting the specific antiinflammatory properties of AF. They also demonstrated that postnatal administration of porcine $\mathrm{AF}$ as minimal enteral nutrition to preterm neonates led to an increase in body weight gain, altered bacterial colonization, reduced the severity of NEC, and induced differential expression of mRNA coding for genes involved in gut inflammatory responses. The beneficial effects of AF were only seen when AF was provided both as minimal enteral nutrition during the parenteral period and the following enteral nutrition period, whereas providing AF only during the enteral period did not show similar effects.

An important topic raised by the study is the fact that the growth-promoting activity of AF on fetal intestinal cells is less as compared with BM (40), and the concentrations of immune-modulatory factors, like TGF- $\alpha$, are only $10-15 \%$ of that found in colostrum (81). Further studies are required to investigate whether enteral supplementation of concentrated AF to PI during parenteral nutrition, or together with enteral milk feeding, will provide the desired concentrations of immune-modulatory and growth factors, which will in turn provide the desired protective effects on the GIT.
Christensen et al. (82) tested simulated AF (solution containing erythropoietin plus G-CSF) in very low birth weight infants for 14 days showed that simulated AF was well tolerated and significantly higher caloric intake compared with the control group. The same group tested simulated AF solution in infants with feeding intolerance and found that it was associated with better tolerance of milk feeding (83).

We also investigated the role of administration of enteral $\mathrm{AF}$ on the incidence and severity of experimental NEC-like GIT mucosal inflammation (38). We used a hypoxiahypothermia model of experimental NEC. We showed significantly decreased incidence and severity of NEC in rat pups who received $30 \% \mathrm{AF}$ as compared with the control group (rats which were purely formula fed). We also demonstrated that AF supplementation in enteral feeds reduced tissue expression of inflammatory cytokines in rat pups with experimental NEC. Next, we wanted to observe the protective effects of individual trophic factors present in AF against the development of experimental NEC. We found that HGF was the most abundant growth factor present in rat AF. We investigated the role of HGF in AF on experimental NEClike injury in rat pups and found that the incidence and severity of experimental NEC in rat pups was significantly lower in the HGF group as compared with the control group. In this study, we showed that AF significantly increased cell proliferation, migration, and survival in vitro. This effect was blunted when an HGF-receptor inhibitor was added. This study identified HGF as a key bioactive component of AF. These findings emphasized swallowed AF as a key maturational influence in the developing intestine. NEC is a disease of PI and may be due to the fact that preterm delivery leads to interruption of AF swallowing and hence missed availability of AF borne trophic factors making PI more vulnerable to NEC. This emphasizes that enteral supplementation of AF in PI may be a potential way to provide trophic factors, which the infant would have received as a fetus in utero.

\section{ROLE OF AMNIOTIC FLUID STEM CELLS}

Stem cells have become a clinical therapeutic option for other intestinal inflammatory diseases that share some features with NEC, such as inflammatory bowel disease (84). The stem cells for such disorders are derived from bone marrow. The application of AF-derived stem cells is novel and is specific to prevention and treatment of NEC. Currently, such potential of AF stem cells is a field with extremely active research.

The intestinal epithelium has an extremely rapid turnover, with the entire epithelium being renewed every 4-5 days (85). Intestinal stem cells in the crypt divide at a very fast rate, which yields cells that differentiate into enterocytes, enteroendocrine cells, goblet cells, and paneth cells, which then migrate towards the villus tip. The wingless integration site signaling pathway drives this rapid division in the crypts (86). At the villus tip, apoptosis is responsible for the normal turnover of epithelial cells (87). This is followed by the autophagic clearance of apoptotic remnants. Under normal conditions, the rate of cell proliferation in the crypts is equal 
to the rate of cell loss at the tips by apoptosis and autophagy. NEC is characterized by an increase in apoptosis, which has been observed in both experimental studies (88) and human NEC (89). Recent evidence also suggests that autophagy is increased in experimental and human NEC (90). It has also been demonstrated that proliferation and migration of epithelial cells is markedly decreased under such conditions (91). This may be secondary to damage or loss of the intestinal stem cell niche. Therefore, preventative methods to decrease loss of intestinal stem cells or therapies to restore the stem cell niche may be of clinical benefit.

The discovery of stem cells in the AF has led to widespread research in the role of stem cells and their effect on NEC. The presence of a subpopulation of AF cells with mesenchymal features, which were able to proliferate in vitro more rapidly than comparable fetal and adult cells, was described in 2001 (92). Subsequently, it was demonstrated that AF could be an abundant source of fetal cells that exhibit a multilineage differentiation potential similar to that of bone marrowderived stem cells (93). This was done by demonstrating a subpopulation of cells within AF, which were Oct-4 positive. The Oct- 4 protein is extremely important in the maintenance of stem cells and each established mammalian pluripotent stem cell line expresses Oct-4, which rapidly disappears when the cells differentiate (94). This was the first evidence that AF could contain pluripotent stem cells. A study published in 2009 hypothesized that intestinal progenitor cells in the AF (AF stem cells) may offer a novel strategy for intestinal restitution (95). To address this hypothesis, the authors attempted to characterize the intestinal stem cell markers in AF. They obtained AF from pregnant mice and these mice were c-sectioned on the corresponding days, and the AF was aspirated without contact with the placenta. Subsequently, RNA was extracted and rtPCR was performed for Lgr 5 and Musashi-1, the selected intestinal stem cell markers for the study. Human AF cells were also cultured and protein extraction and immunoblots were performed for Lgr 5 and Musashi-1. The study demonstrated that AF cells in mice expressed Lgr 5 as early as 13.5 weeks of gestation, whereas Musashi-1 was expressed as early 12.5 weeks of gestation. Both markers were expressed in human AF beginning from the 14th week of gestation. This study definitively demonstrated that AF cells express intestinal stem cell markers, and the possibility of obtaining intestinal progenitor cells in the AF was a critical step in their potential use in repair of the intestinal barrier damage secondary to NEC.

Zani et al. used AF stem cells in a rat model of NEC. AF stem cells were administered intraperitoneally and their controls (bone marrow mesenchymal stem cells (BM-MSC) and rat skeletal muscle myoblasts) were analyzed for survival, behavior, bowel imaging (MRI scan), histology, bowel absorption and motility, immunofluorescence for AF stem cell detection, degree of gut inflammation and enterocyte apoptosis, and proliferation (96). Clonal AF stem cells were cultured from transgenic rates and BM-MSC were obtained from the femurs of adult rats. They demonstrated that NEC rats injected with AF stem cells showed improved survival at 7 days, had improved clinical sickness scores, showed reduced apoptosis in the villi and also demonstrated reduced lipid peroxidation and neutrophil infiltration, and showed increased villus cell proliferation and migration as compared with controls. The study also showed that at $96 \mathrm{~h}$, the macroscopic appearance of the gut was similar to rats fed with $\mathrm{BM}$, and there was less evidence of damage and necrosis, and MRI of NEC rats injected with AF showed significantly less bowel dilation as compared with controls.

The mechanism of such effects on NEC rats was hypothesized to be due to a cyclooxygenase-2 (COX-2)related pathway. Inducible COX-2, which is normally at low levels in intestine reduces enterocyte apoptosis, (97) diminishes inflammation (98) and promotes epithelial proliferation. Hence, to test this hypothesis, a survival study using COX-1 and COX-2 inhibitors was performed. Breastfed and NEC rats receiving either $\mathrm{AF}$ stem cells or control solution were randomized to receive either a COX-1 inhibitor or a combined COX-1/COX-2 inhibitor or a selective COX-2

Table 3. The timeline of important studies looking at the protective role of amniotic fluid in the setting of necrotizing enterocolitis

\begin{tabular}{|c|c|c|}
\hline Study name & Important finding & $\begin{array}{l}\text { Primary author } \\
\text { and journal }\end{array}$ \\
\hline $\begin{array}{l}\text { Amniotic fluid inhibits Toll-like receptor } 4 \text { signaling in the fetal } \\
\text { and neonatal intestinal epithelium. }\end{array}$ & $\begin{array}{l}\text { AF instillation into gastrointestinal tract of mice markedly reduces } \\
\text { the extent of TLR4 signaling within the intestinal mucosa via the } \\
\text { activation of the epidermal growth factor receptor (EGFR). }\end{array}$ & Good et al. (80) \\
\hline $\begin{array}{l}\text { Postnatal amniotic fluid intake reduces gut inflammatory } \\
\text { responses and necrotizing enterocolitis in preterm neonates. }\end{array}$ & $\begin{array}{l}\text { Pigs fed AF during parenteral and enteral nutrition had lower NEC } \\
\text { scores and downregulation of inflammatory mediators of NEC. }\end{array}$ & Siggers et al. (67) \\
\hline $\begin{array}{l}\text { Amniotic fluid stem cells improve survival and enhance repair } \\
\text { of damaged intestine in necrotizing enterocolitis via a COX-2- } \\
\text { dependent mechanism. }\end{array}$ & $\begin{array}{l}\text { NEC rats injected with AF stem cells showed improved survival at } \\
7 \text { days with reduced apoptosis and neutrophil infiltration together } \\
\text { with increased villus cell proliferation and migration. }\end{array}$ & Zani et al. (97) \\
\hline
\end{tabular}

Abbreviations: AF, amniotic fluid; NEC: necrotizing enterocolitis. 
inhibitor. The beneficial effects of AF stem cells on survival were abolished in the presence of a combined a COX-1/ COX-2 inhibitor and selective COX-2 inhibitor but not in the presence of a selective COX-1 inhibitor. This demonstrated that the effect of AF stem cells in NEC rats was likely mediated by the inducible COX-2 mechanism.

Table 3 summarizes the timeline of important studies looking at the protective role of amniotic fluid in the setting of necrotizing enterocolitis.

BARRIERS TO AF STEM CELL USE AND FUTURE DIRECTIONS AF stem cells are a potential cell source for therapeutic applications. However, a major obstacle to the manufacturing of clinical-grade stem cells is the need for good manufacturing practices for cryopreservation, storage, and distribution of these cells. Most current cryopreservation methods use the potentially toxic cryoprotectant dimethyl-sulfoxide in the presence of animal serum proteins that prevent direct use of these cells in human therapeutic applications. A study by Seo et al. (99) demonstrated that AF stem cells can be cryopreserved with one-quarter of the standard dimethylsulfoxide concentration after the addition of disaccharides, antioxidants, and caspase inhibitors.

\section{WHAT ABOUT SIMULATED AMNIOTIC FLUID}

Calhoun et al. initiated studies on the enteral administration of a simulated amniotic fluid (SAF) solution (100). This SAF is a sterile, noncaloric, isotonic, growth factor-containing experimental solution that is patterned after the AF found in the mid-second trimester of pregnancy (100). The two growth factors in this solution-recombinant granulocyte colonystimulating factor (rG-CSF) and recombinant erythropoietin (rEPO) - are found abundantly in human milk and AF, have a key role in the developing gut, and are relatively resistant to breakdown by digestion (101). Receptors for G-CSF and EPO are abundant on the luminal surface of the fetal intestinal villi (101). To provide the same concentration of G-CSF and EPO as that, which is swallowed by the fetus during mid-second trimester of pregnancy, rG-CSF and rEPO are concentrated tenfold in SAF (101).

To assess the tolerance of SAF enterally administered to preterm neonates, 30 patients were divided into three groups (102). Each group received 5, 10, or $20 \mathrm{ml} / \mathrm{kg} /$ day of SAF for 3 days. There was no evidence of intolerance measured by increased gastric residuals, increased abdominal girth, diarrhea, blood pressure changes, rash, NEC, or intestinal perforation. This study showed that enteral administration of an AF-patterned solution was well tolerated in doses up to $20 \mathrm{ml} / \mathrm{kg} /$ day (103).

A study by Christensen et al. examined the degree of feeding intolerance among very low birth weight infants after administration of oral gastric boluses of a solution patterned after AF. This solution was given along with milk feedings and was discontinued when milk feedings reached $80 \mathrm{ml} / \mathrm{kg} /$ day. The control group consisted of VLBW infants receiving milk feedings without the AF-patterned solution. The study showed that during the first 14 days after birth, the study group had a median of 26.5 enteral cal $/ \mathrm{kg} / \mathrm{day}$, whereas the control group had 8.5 enteral cal $/ \mathrm{kg} /$ day. During the first 21 days after birth, the numbers were 56.9 and 19.2 enteral $\mathrm{cal} / \mathrm{kg} / \mathrm{day}$. The limitations of the study were that it was not randomized or blinded, and the test group was small in number $(N=14)(82)$.

Corpeleijn et al. (103) investigated the effect of only one growth factor, IGF-1, as opposed to the two growth factors found in SAF. Administration of IGF-1 was initiated shortly after birth and every $3 \mathrm{~h}$ thereafter to infants who were not being fed. The duration of the intervention for this trial was 28 days. To determine the effect of IGF-1 supplementation rather than the combined effect of IGF-1 and growth factors found in BM, study participants received only formula. The study showed improved feeding tolerance by assessing total enteral $\mathrm{kcal} / \mathrm{kg} /$ day intake.

\section{ETHICAL QUESTIONS BEFORE USING AF IN PRETERM INFANTS}

Although the potential for the postnatal administration of AF is exciting, many ethical issues remain with respect to the collection and use of AF.

How should AF be collected? Should it be collected via amniocentesis or just before delivery?

What gestational age is the optimum time for AF collection? Because vaginal delivery may contaminate AF, should it only be collected during cesarean deliveries if not collected via amniocentesis?

Should the AF that is used, have to be from the newborn's mother or can "donor AF" be used as well?

Should AF be collected from mothers who deliver prematurely even though the risk of contamination secondary to chorioamnionitis is higher?

There is need for additional large animal studies beyond rat and mouse studies to evaluate continued impact and safety of AF administration?

What is the appropriate method of effectively sterilizing AF? Can AF stem cells be safely administered without causing other deleterious effects?

Such ethical and storage issues demonstrate that we are still in the early phases of use of AF as a potential therapeutic option. However, the role of AF in the setting of NEC is an extremely exciting area of research. There is research evidence that demonstrates the beneficial role of AF supplementation. However, the first rule of medicine is "do no harm" and hence appropriate randomized controlled studies and experience with respect to storage, use, and outcomes are essential before AF can be used routinely and safely.

Disclosure: The authors declare no conflict of interest.

\section{REFERENCES}

1. Bell MJ, Ternberg JL, Feigin RD, et al. Neonatal necrotizing enterocolitis. Ann Surg 1978;187:1-7. 
2. Warner BB, Tarr PI. Necrotizing enterocolitis and preterm infant gut bacteria. Semin Fetal Neonat Med 2016;21:394-9.

3. Thompson AM, Bizzarro MJ. Necrotizing enterocolitis in newborns. Drugs 2008;68:1227-38.

4. Patel RM, Kandefer S, Walsh MC, et al. Causes and timing of death in extremely premature infants from 2000 through 2011. N Engl J Med 2015;372:331-40.

5. Lin PW, Stoll BJ. Necrotising enterocolitis. Lancet 2006;368:1271-83.

6. Panigrahi P. Necrotizing enterocolitis. Pediatr Drugs 2006;8:151-65.

7. Pickard SS, Feinstein JA, Popat RA, Huang L, Dutta S. Short- and long-term outcomes of necrotizing enterocolitis in infants with congenital heart disease. Pediatrics 2009;123:e901-6.

8. Ganapathy V, Hay JW, Kim JH. Costs of necrotizing enterocolitis and cost-effectiveness of exclusively human milk-based products in feeding extremely premature infants. Breastfeed Med 2012;7:29-37.

9. Kantorowska A, Wei JC, Cohen RS, Lawrence RA, Gould JB, Lee HC. Impact of donor milk availability on breast milk use and necrotizing enterocolitis rates. Pediatrics 2016;137:1-8.

10. Lemyre B, Xiu W, Bouali NR, et al. A decrease in the number of cases of necrotizing enterocolitis associated with the enhancement of infection prevention and control measures during a staphylococcus aureus outbreak in a neonatal intensive care unit. Infect Contr Hosp Epidemiol 2012;33:29-33.

11. Anand RJ, Leaphart CL, Mollen KP, Hackam DJ. The role of the intestinal barrier in the pathogenesis of necrotizing enterocolitis. Shock 2007;27:124-33.

12. Sodhi CP, Shi XH, Richardson WM, et al. Toll-like receptor-4 inhibits enterocyte proliferation via impaired $\beta$-catenin signaling in necrotizing enterocolitis. Gastroenterology 2010;138:185-96.

13. Lu P, Sodhi CP, Hackam DJ. Toll-like receptor regulation of intestinal development and inflammation in the pathogenesis of necrotizing enterocolitis. Pathophysiology 2014;21:81-93.

14. Vongbhavit K, Underwood MA. Prevention of necrotizing enterocolitis through manipulation of the intestinal microbiota of the premature infant. Clin Ther 2016;38:716-32.

15. Arboleya S, Ang L, Margolles A, et al. Deep 16S rRNA metagenomics and quantitative PCR analyses of the premature infant fecal microbiota. Anaerobe 2012;18:378-80.

16. Caplan MS, Simon D, Jilling T. The role of PAF, TLR, and the inflammatory response in neonatal necrotizing enterocolitis. Semin Pediatr Surg 2005;14:145-51.

17. Hackam DJ, Upperman JS, Grishin A, Ford HR. Disordered enterocyte signaling and intestinal barrier dysfunction in the pathogenesis of necrotizing enterocolitis. Semin Pediatr Surg 2005;14:49-57.

18. Ford HR, Watkins S, Reblock K, et al. The role of inflammatory cytokines and nitric oxide in the pathogenesis of necrotizing enterocolitis. J Pediatr Surg 1997;32:275-82.

19. Underwood MA, Sherman MP. Nutritional characteristics of amniotic fluid. NeoReviews 2006;7:38-47.

20. Brace RA. Physiology of amniotic fluid volume regulation. Clin Obstet Gynecol 1997;40:280-9.

21. Trahair JF, Harding RR. "Ultrastructural anomalies in the fetal small intestine indicate that fetal swallowing is important for normal development: an experimental study". Virchows Arch A Pathol Anat Histopathol 420:305-12.

22. Trahair JF, Harding R. The role of ingestion in the development of the small intestine in fetal sheep. Q J Exp Physiol 71:99-104.

23. Condino AA, Barleycorn AA, Lu W, Maheshwari A, Christensen RD, Calhoun DA. Abnormal intestinal histology in neonates with congenital anomalies of the gastrointestinal tract. Neonatology 2004;85: $145-50$.

24. Drozdowski L, Thomson AB. Intestinal hormones and growth factors: Effects on the small intestine. World J Gastroenterol 2009;15:385-406.

25. Maheshwari A. Role of cytokines in human intestinal villous development. Clin Perinatol 2004;31:143-55.
26. Mohankumar K, Namachivayam K, Ho TT, Torres BA, Ohls RK, Maheshwari A. Cytokines and growth factors in the developing intestine and during necrotizing enterocolitis. Semin Perinatol 2017;41:52-60.

27. Battersby AJ, Khara J, Wright VJ, Levy O, Kampmann B. Antimicrobial proteins and peptides in early life: ontogeny and translational opportunities. Front Immunol 2016;7:309.

28. Espinoza J, Chaiworapongsa T, Romero R, et al. Antimicrobial peptides in amniotic fluid: defensins, calprotectin and bacterial/permeabilityincreasing protein in patients with microbial invasion of the amniotic cavity, intra-amniotic inflammation, preterm labor and premature rupture of membranes. J Matern Fetal Neonat Med 2003;13:2-21.

29. Salzman NH, Polin RA, Harris MC, et al. Enteric defensin expression in necrotizing enterocolitis. Pediatr Res 1998;44:20-6.

30. Jenke ACW, Zilbauer M, Postberg J, Wirth S. Human $\beta$-defensin 2 expression in ELBW infants with severe necrotizing enterocolitis. Pediatr Res 2012;72:513-20.

31. Cohen S. Isolation of a mouse submaxillary gland protein accelerating incisor eruption and eyelid opening in the new-born animal. J Biol Chem 1962;237:1555-62.

32. Playford RJ, Wright NA. Why is epidermal growth factor present in the gut lumen? Gut 1996;38:303-5.

33. Lacy ER. Epithelial restitution in the gastrointestinal tract. J Clin Gastroenterol 1988: 10.

34. Playford RJ, Marchbank T, Calnan DP, et al. Epidermal growth factor is digested to smaller, less active forms in acidic gastric juice. Gastroenterology 1995;108:92-101.

35. Dvorak B, Halpern MD, Holubec H, et al. Epidermal growth factor reduces the development of necrotizing enterocolitis in a neonatal rat model. Am J Physiol Gastrointest Liver Physiol 2002;282:G156-64.

36. Clark JA, Doelle SM, Halpern MD, et al. Intestinal barrier failure during experimental necrotizing enterocolitis: protective effect of EGF treatment. Am J Physiol Gastrointest Liver Physiol 2006;291:G938-49.

37. Clark JA, Lane RH, Maclennan NK, et al. Epidermal growth factor reduces intestinal apoptosis in an experimental model of necrotizing enterocolitis. Am J Physiol Gastrointest Liver Physiol 2005;288: G755-62.

38. Jain SK, Baggerman EW, Mohankumar K, et al. Amniotic fluid- borne hepatocyte growth factor protects rat pups against experimental necrotizing enterocolitis. Am J Physiol Gastrointest Liver Physiol 2014;306:G361-9.

39. Burrin DG, Stoll B. Key nutrients and growth factors for the neonatal gastrointestinal tract. Clin Perinatol 2002;29:65-96.

40. Hirai C, Ichiba H, Saito M, Shintaku H, Yamano T, Kusuda S. Trophic effect of multiple growth factors in amniotic fluid or human milk on cultured human fetal small intestinal cells. J Pediatr Gastroenterol Nutr 2002;34:524-8.

41. Claud EC, Savidage T, Walker WA. Modulation of human intestinal epithelial cell IL-8 secretion by human milk factors. Pediatr Res 2003;53: 419-25.

42. Maheshwari A, Kelly DR, Nicola T, et al. TGF- $\beta 2$ suppresses macrophage cytokine production and mucosal inflammatory responses in the developing intestine. Gastroenterology 2011;140:242-53.

43. Letterio JJ, Geiser AG, Kulkarni AB, Roche NS, Sporn MB, Roberts AB. Maternal rescue of transforming growth factor beta 1 null mice. Science 1994;264:1936-8.

44. Lebman DA, Edmiston JS. The role of TGF-beta in growth, differentiation, and maturation of B lymphocytes. Microbes Infect 1999;1: 1297-304.

45. Bloomfield FH, Bauer MK, van Zijl PL, Gluckman PD, Harding JE. Amniotic IGF-I supplements improve gut growth but reduce circulating IGF-I in growth-restricted fetal sheep. Am J Physiol Endocrinol Metab 2002;282:E259-69.

46. Chailler P, Basque JR, Corriveau L, Menard D. Functional characterization of the keratinocyte growth factor system in human fetal gastrointestinal tract. Pediatr Res 2000;48:504-10. 
47. Semba RD, Juul SE. Erythropoietin in human milk: physiology and role in infant health. J Hum Lact 2002;18:252-61.

48. Calhoun DA, Lunoe M, Du Y, Christensen RD. Granulocyte colonystimulating factor is present in human milk and its receptor is present in human fetal intestine. Pediatrics 2000;105:e7.

49. Barmeyer C, Horak I, Zeitz M, Fromm M, Schulzke JD. The interleukin2-deficient mouse model. Pathobiology 2003;70:139-42.

50. Hogaboam CM, Vallance BA, Kumar A, et al. Therapeutic effects of interleukin-4 gene transfer in experimental inflammatory bowel disease. J Clin Invest 1997;100:2766-76.

51. Rollwagen F, Yu Z-Y, Li Y-Y, Pacheco N. IL-6 rescues enterocytes from hemorrhage induced apoptosis in vivo and in vitro by abcl-2 mediated mechanism. Clin Immunol Immunopathol 1998;89:205-13.

52. Welniak LA, Khaled AR, Anver MR, et al. Gastrointestinal cells of IL-7 receptor null mice exhibit increased sensitivity to irradiation. J Immunol 2001;166:2924-8.

53. Peterson RL, Bozza MM, Dorner AJ. Interleukin-11 induces intestinal epithelial cell growth arrest through effects on retinoblastoma protein phosphorylation. Am J Pathol 1996;149:895-902.

54. Cummins AG, Thompson FM. Effect of breast milk and weaning on epithelial growth of the small intestine in humans. Gut 2002;51: 748-54.

55. Commare CE, Tappenden KA. Development of the infant intestine: implications for nutrition support. Nutr Clin Pract 2007;22:159-73.

56. Newburg DS, Walker WA. Protection of the neonate by the innate immune system of developing gut and of human milk. Pediatr Res 2007;61:2-8.

57. Goldman AS, Garza C, Nichols BL, Goldblum RM. Immunologic factors in human milk during the first year of lactation. J Pediatr 1982;100: $563-7$.

58. Buccigrossi V, De Marco G, Bruzzese E, et al. Lactoferrin induces concentration-dependent functional modulation of intestinal proliferation and differentiation. Pediatr Res 2007;61:410-14.

59. Lucas A, Cole TJ. Breast milk and neonatal necrotizing enterocolitis. Lancet 1990;336:1519-23.

60. Halpern MD, Dvorak B. Does abnormal bile acid metabolism contribute to NEC? Semin Perinatol 2008;32:114-21.

61. Halpern MD, Holubec H, Saunders TA, et al. Bile acids induce ileal damage during experimental necrotizing enterocolitis. Gastroenterology 2006;130:359-72.

62. Newburg DS, He Y. Neonatal gut microbiota and human milk glycans cooperate to attenuate infection and inflammtion. Clin Obstet Gynecol 2015;58:814-26.

63. Good M, Sodhi CP, Yamaguchi Y, et al. The human milk oligosaccharide 2 -fucosyllactose attenuates the severity of experimental necrotising enterocolitis by enhancing mesenteric perfusion in the neonatal intestine. Br J Nutr 2016;116:1175-87.

64. Meinzen-Derr J, Poindexter B, Wrage L, Morrow AL, Stoll B, Donovan EF. Role of human milk in extremely low birth weight infants' risk of necrotizing enterocolitis or death. J Perinatol 2009;29:57-62.

65. Good M, Sodhi CP, Hackam DJ. Evidence based feeding strategies before and after the development of necrotizing enterocolitis. Expert Rev Clin Immunol 2014;10:875-4.

66. Siggers J, Ostergaard MV, Siggers RH, et al. Postnatal amniotic fluid intake reduces gut inflammatory responses and necrotizing enterocolitis in preterm neonates. Am J Physiol Gastrointest Liver Physiol 2013;304: G864-75.

67. Stadnyk AW. Cytokine production by epithelial cells. FASEB J 1994;8: 1041-7.

68. Yang SK, Eckmann L, Panja A, Kagnoff MF. Differential and regulated expression of C-X-C, C-C and C-chemokines by human colon epithelial cells. Gastroenterology 1997;113:1214-23.

69. Muzio M, Natoli G, Saccani S, Levrero M, Mantovani A. The human toll signaling pathway: divergence of nuclear factor kappaB and JNK/SAPK activation upstream of tumor necrosis factor receptor-associated factor 6 (TRAF6). J Exp Med 1998;187:2097-101.
70. Nanthakumar NN, Fusunyan RD, Sanderson I, Walker WA. Inflammation in the developing human intestine: a possible pathophysiologic contribution to necrotizing enterocolitis. Proc Natl Acad Sci USA 2000;97:6043-8.

71. Jilling T, Simon D, Lu J, et al. The roles of bacteria and TLR4 in rat and murine models of necrotizing enterocolitis. J. Immunol 2006;177:3273-82.

72. Sharma R, Tepas JJ III, Hudak ML III, et al. Neonatal gut barrier and multiple organ failure: role of endotoxin and proinflammatory cytokines in sepsis and necrotizing enterocolitis. J Pediatr Surg 2007;42:454-61.

73. Chan KL, Ho JC, Chan KW, Tam PK. A study of gut immunity to enteral endotoxin in rats of different ages: a possible cause for necrotizing enterocolitis. J Pediatr Surg 2002;37:1435-40.

74. Akira SK, Takeda T, Kaisho T. Toll-like receptors: critical proteins linking innate and acquired immunity. Nat Immunol 2001;2:675-80.

75. Lemaitre B, Nicolas E, Michaut L, Reichhart JM, Hoffmann JA. The dorsoventral regulatory gene cassette spatzle/Toll/cactus controls the potent antifungal response in Drosophila adults. Cell 1996;86:973-83.

76. Palsson-Mcdermott EM, O'neill LAJ. Signal transduction by the lipopolysaccharide receptor, Toll-like receptor-4. Immunology 2004;113: 153-62.

77. Leaphart CL, Cavallo J, Gribar SC, et al. A critical role for TLR4 in the pathogenesis of necrotizing enterocolitis by modulating intestinal injury and repair. J Immunol 2007;179:4808-20.

78. Jantscher-Krenn E, Zherebtsov M, Nissan C, et al. The human milk oligosaccharide disialyllacto_N-tetraose prevents necrotising enterocolitis in neonatal rats. Gut 2012;61:1417-25.

79. Good M, Siggers RH, Sodhi CP, et al. Amniotic fluid inhibits Toll-like receptor 4 signaling in the fetal and neonatal intestinal epithelium. Proc Natl Acad Sci USA 2012;109:11330-5.

80. Good M, Sodhi CP, Egan CE, et al. Breast milk protects against the development of necrotizing enterocolitis through inhibition of Toll-like receptor 4 in the intestinal epithelium via activation of the epidermal growth factor receptor. Mucosal Immunol 2015;8:1166-79.

81. Sangild PT, Mei J, Fowden AL, Xu RJ. The prenatal porcine intestine has low transforming growth factor-ligand and receptor density and shows reduced trophic response to enteral diets. Am J Physiol Regul Integr Comp Physiol 2009;296:R1053-62.

82. Christensen RD, Havranek T, Gerstmann DR, Calhoun DA. Enteral administration of a simulated amniotic fluid to very low birth weight neonates. J Perinatol 2005;25:380-5.

83. Barney CK, Lambert DK, Alder SC, Scoffield SH, Schmutz N, Christensen RD. Treating feeding intolerance with an enteral solution patterned after human amniotic fluid: a randomized, controlled, masked trial. J Perinatol 2007;27:28-31.

84. Cassinotti A, Annaloro C, Ardizzone S, et al. Autologous haematopoietic stem cell transplantation without CD34+ cell selection in refractory Crohn's disease. Gut 2008;57:211-7.

85. Eaton S, Zani A, Pierro A, De Coppi P. Stem cells as a potential therapy for necrotizing enterocolitis. Expert Opin Biol Ther 2013;13:1683-9.

86. Clevers H, Batlle E. SnapShot: the intestinal crypt. Cell 2013;152:1198.

87. Hall PA, Coates PJ, Ansari B, Hopwood D. Regulation of cell number in the mammalian gastrointestinal-tract-the importance of apoptosis. J Cell Sci 1994;107:3569-77.

88. Jilling T, Lu J, Jackson M, Caplan MS. Intestinal epithelial apoptosis initiates gross bowel necrosis in an experimental rat model of neonatal necrotizing enterocolitis. Pediatr Res 2004;55:622-9.

89. Eaton S, Sebire NJ, Thyoka M, Pierro A. Histological and immunohistochemical features associated with outcome in neonatal necrotizing enterocolitis. Eur J Pediatr Surg 2014;24:51-6.

90. Maynard AA, Dvorak K, Khailova L, et al. Epidermal growth factor reduces autophagy in intestinal epithelium and in the rat model of necrotizing enterocolitis. Am J Physiol Gastrointest Liver Physiol 2010;299:G614-22.

91. Feng J, Besner GE. Heparin-binding epidermal growth factor-like growth factor promotes enterocyte migration and proliferation in neonatal rats with necrotizing enterocolitis. J Pediatr Surg 2007;42:214-0. 
92. Kaviani A, Perry TE, Dzakovic A, Jennigns RW, Ziegler MM, Fauza Do. The amniotic fluid as a source of cells for fetal tissue engineering. J Pediatr Surg 2001;36:1662-5.

93. Prusa AR, Marton E, Rosner M, et al. Oct-4-expressing cells in human amniotic fluid: a new source for stem cell research? Hum Reprod 2003;18:1489-93.

94. Pesce M, Schöler HR. Oct-4: gatekeeper in the beginnings of mammalian development. Stem Cells 2001;19:271-8.

95. Emami CN, Upperman J, Ford HR, et al. Amniotic fluid cells express intestinal stem cell markers of Lgr 5 and Musashi-1. J Am Coll Surg 2009;209:S84.

96. Zani A, Cananzi M, Fascetti-Leon F, et al. Amniotic fluid stem cells improve survival and enhance repair of damaged intestine in necrotising enterocolitis via a COX-2 dependent mechanism. Gut 2014;63:300-9.

97. Tessner TG, Muhale F, Riehl TE, et al. Prostaglandin E2 reduces radiation-induced epithelial apoptosis through a mechanism involving AKT activation and bax translocation. J Clin Invest 2004;114:1676-85.

98. Gilroy DW, Colville-Nash PR, Willis D, et al. Inducible cyclooxygenase may have anti-inflammatory properties. Nat Med 1999;5:698-701.

99. Seo JM, Sohn MY, Suh JS, Atala A, Yoo JJ, Shon YH. Cryopreservation of amniotic fluid-derived stem cells using natural cryoprotectants and low concentrations of dimethylsulfoxide. Cryobiology 2011;62:167-73.

100. Calhoun DA, Christensen RD. Hematopoietic growth factors in neonatal medicine: the use of enterally administered hematopoietic growth factors in the neonatal intensive care unit. Clin Perinatol 2004;31: 169-82.

101. Smith CG. In the critically ill, nothing-by-mouth Infant, would enteral administration of simulated amniotic fluid improve feeding tolerance compared with the current practice of no therapy? An evidencebased review. Neonat Netw J Neonat Nurs 2011;30:105-15.
102. Sullivan SE, Calhoun DA, Maheshwari A, et al. Tolerance of simulated amniotic fluid in premature neonates. Ann Pharmacother 2002;36: 1518-24.

103. Corpeleijn WE, van Vliet I, de Gast-Bakker DA, et al. Effect of enteral IGF-1 supplementation on feeding tolerance, growth, and gut permeability in enterally fed premature neonates. J Pediatr Gastroenterol Nutr 2008;46:184-90.

104. Juul SE, Ledbetter DJ, Joyce AE, Dame C, Christensen RD, Zhao Y. Erythropeitin acts as a trophic factor in neonatal rat intestine. Gut 2001;49:182-9.

105. Takahata Y, Takada H, Nomura A, et al. Interleukin-18 in human milk. Pediatr Res 2001;50:268-72.

106. Madsen KL. Inflammatory bowel disease: lessons from the IL-10 gene-deficient mouse. Clin Invest Med 2001;24:250-7.

107. Lonergan M, Aponso D, Marvin KW, et al. Tumor necrosis factor-related apoptosis-inducing ligand (TRAIL), TRAIL receptors, and the soluble receptor osteoprotegerin in human gestational membranes and amniotic fluid during pregnancy and labor at term and preterm. J Clin Endocrinol Metab 2003;88:3835-44.

108. Tremblay E, Monfils S, Menard D. Epidermal growth factor influences cell proliferation, glycoproteins, and lipase activity in human fetal stomach. Gastroenterology 1997;112:1188-96.

109. Dvorak B, Williams CS, McWilliam DL, et al. Milk-borne epidermal growth factor modulates intestinal transforming growth factor-alpha levels in neonatal rats. Pediatr Res 2000;47:194-200.

110. Vuorela P, Andersson S, Carpen O, Ylikorkala O, Halmesmaki E. Unbound vascular endothelial growth factor and its receptors in breast, human milk, and newborn intestine. Am J Clin Nutr 2000;72:1196-201.

111. Maheshwari A, Lu W, Lacson A, et al. Effects of interleukin-8 on the developing human intestine. Cytokine 2002;20:256-67. 